\title{
Effects of Compost on PFAS Uptake by Lettuce
}

\author{
YuANBO LI, ${ }^{1}$ Yu ZHI ${ }^{2}$ StePhen W. BROOME, ${ }^{3}$
} DETLEF KNAPPE, ${ }^{2}$ AND OWEN W. DUCKWORTH ${ }^{3}$

${ }^{1}$ Institute of Plant Protection, Chinese Academy of Agricultural Sciences, Beiijing, China

${ }^{2}$ Department of Civil, Construction, and Environmental Engineering, NC State University, Raleigh, North Carolina 27695, United States

${ }^{3}$ Department of Crop and Soil Sciences, NC State University, Raleigh, NC 27695

Food crops uptake of per- and polyfluoralkyl substances (PFAS) from contaminated soil due to reuse practices (e.g., reclaimed water irrigation and biosolids amendment) or uncontrolled releases have raised concerns about human exposure through dietary intake, with potential health implications. However, the strategies to mitigate the plant uptake of these chemicals from soil have not yet been well established.. Organic carbon has shown an excellent capacity for sorption of hydrophobic PFAS, thereby reducing their bioavailability. In this study, soil was amended with commercialized compost at three rates $(0,5,10$ and $20 \%)$ to evaluate the effects on the mitigation the mixture of nine commonly detected PFAS (e.g., PFMOAA, GenX, PFBS, PFHxS, PFOS, 6:2 FtS, 4:2 FtS, 8:2 FtS, and 10:2 FtS) uptake by lettuce. The pots uptake experiment was conducted in pots in a greenhouse; the mixture of PFAS chemicals was spiked into the soil at two concentration levels, i.e., $10 \mathrm{ng} / \mathrm{g}$ and 100 $\mathrm{ng} / \mathrm{g}$. The pots were irrigated daily with deionized water to maintain soil water content at $60 \%$ by monitoring the pot weights. All experimental pots were prepared in triplicate, including the PFAS-free control. After 50 days of exposure, the PFAS concentrations in lettuce roots and shoots grown in the soil with different rates of compost will be comparative analyzed. In addition, the biomass of lettuces will also be measured to examine if the compost amendment could reduce the lettuce uptake of PFAS and at the same time increase the vegetable biomass. 